\title{
Measles, month of birth, and Crohn's disease
}

\author{
N Haslam, J F Mayberry, A B Hawthorne, R G Newcombe, G K T Holmes, C S J Probert
}

Gloucestershire Royal

Hospital, Great

Western Road,

Gloucester, UK

N Haslam

Leicester General Hospital, Gwendolen Road, Leicester, UK

J F Mayberry

University Hospital of Wales, Cardiff, UK

A B Hawthorne

University of Wales, College of Medicine, Cardiff, UK

R G Newcombe

Derbyshire Royal Infirmary, London Road, Derby, UK G K T Holmes

University Division of Medicine, Bristol Royal Infirmary, Marlborough St, Bristol BS2 8HW, UK C S J Probert

Correspondence to: Dr C S J Probert. Email: C.S.J.Probert@bris.ac.uk

Accepted for publication 19 April 2000

\begin{abstract}
Background-The rise in the incidence of Crohn's disease (CD) suggests the role of an environmental factor in the development of the disease in susceptible individuals. Perinatal exposure to infection has been proposed as such an environmental factor.

Aim-To investigate the influence of birth date on the development of $\mathrm{CD}$ in later life.

Patients and method-Four registers of patients with $\mathrm{CD}$, diagnosed from 1972 to 1989, were combined, and data from 1624 patients were examined. The birth dates of CD patients were compared with national birth figures for three decades (1941-50, 1951-60, and 1961-70) to avoid temporal changes in birth trends, and year of birth was compared with epidemic measles years between 1951 and 1967. Risk ratios with $95 \%$ confidence intervals (CI) and $\chi^{2}$ tests were performed.

Results-There were marginal differences between the birth dates of the $\mathrm{CD}$ patients and those predicted from the general population. Further analysis of both season of birth and year halves revealed a very weak association with the first half of the year (relative risk $1.14 \quad(95 \%$ CI 1.01-1.30)). There was no association between developing $\mathrm{CD}$ and birth during measles epidemics between 1951 and 1967. Conclusions-In utero or perinatal exposure to seasonal environmental factors are unlikely potential aetiological agents in the later development of CD.

(Gut 2000;47:801-803)
\end{abstract}

Keywords: measles; birth date; Crohn's disease; epidemiology

The aetiology of inflammatory bowel disease (IBD) remains unknown. In Cardiff, over a 50 year period, the incidence of Crohn's disease (CD) has increased from 0.18 cases $/ 10^{5}$ population/year to $8.3 \mathrm{cases} / 10^{5} /$ year. ${ }^{1}$ This rise could imply an environmental factor to which genetically susceptible people have been exposed. Researchers from the Royal Free Hospital have suggested that perinatal or in utero factors are important aetiological factors

Table 1 Month of birth for Crohn's disease (CD) patients in four inflammatory bowel disease registers

\begin{tabular}{lrrrrrrrrrrrrr}
\hline & fan & Feb & March & April & May & fune & fuly & Aug & Sept & Oct & Nov & Dec & Total \\
\hline Cardiff cases & 37 & 39 & 43 & 35 & 33 & 40 & 30 & 42 & 37 & 36 & 30 & 22 & 424 \\
Leic cases & 60 & 51 & 57 & 75 & 66 & 55 & 63 & 47 & 53 & 51 & 48 & 44 & 670 \\
TH cases & 10 & 9 & 11 & 12 & 11 & 6 & 6 & 6 & 7 & 9 & 9 & 8 & 104 \\
Derby cases & 38 & 43 & 44 & 46 & 36 & 37 & 39 & 30 & 28 & 31 & 24 & 30 & 426 \\
All CD & 145 & 142 & 155 & 168 & 146 & 138 & 138 & 125 & 125 & 127 & 111 & 104 & 1624
\end{tabular}

Leic, Leicester; TH, Tower Hamlets. in the development of CD. They proposed that early exposure to wild-type or live attenuated measles virus may be of aetiological importance..$^{2-4}$

We hypothesise that if IBD is due to early exposure to infectious agents, or other environmental factors, then season of birth will be associated with an increased risk of developing IBD because perinatal or in utero exposure to environmental factors may be seasonal. In the present study, we have assessed the association between these factors and IBD.

\section{Patients and methods}

We combined four registers of patients with CD who were diagnosed between 1972 and 1989: two registers were hospital based, from Cardiff and Derby, and two were community based, from Leicestershire and Tower Hamlets. ${ }^{5-10}$ The Tower Hamlet and Leicestershire databases were collected using identical methods. ${ }^{5-7}$ Cases were identified retrospectively from both hospital and community sources. The case notes of all potential cases were obtained and examined by two investigators using a standard proforma, based on Lennard-Jones' criteria of case definition. ${ }^{11}$

The Cardiff register was established in 1934 and is now computerised. Initially, this was a hospital based register using the diagnostic coding of all inpatients and outpatients but this has been supplemented with general practitioner cases using a questionnaire ${ }^{89}$ and is essentially a community based register. The notes of these patients are examined and included only if they reach strict diagnostic criteria. Data from Derby are hospital based. ${ }^{10}$ Data were recorded retrospectively from 1951 until 1978 inclusively, and then prospectively. histopathology, and the two consultant gastroenterologists in Derby were examined. The case notes identified were examined and patients were included only if strict diagnostic criteria were achieved. To allow comparison nosed between 1 January 1972 and 31 December 1989 were analysed. Complete data were

Abbreviations used in this paper: CD, Crohn's disease; IBD, inflammatory bowel disease; CI, confidence intervals; RR, relative risk. The records of the hospital activity analysis, between all four registers, only patients diag- 
Table 2 Month of birth for the general population and Crohn's disease (CD) by decade (1941-50; 1951-60; 1961-70)

\begin{tabular}{|c|c|c|c|c|c|c|c|c|c|c|c|c|c|}
\hline & fan & $\mathrm{Feb}$ & Mar & $A p r$ & May & fune & fuly & Aug & Sep & Oct & Nov & $D e c$ & Total \\
\hline Births $41-50$ & 121568 & 113544 & 127964 & 123961 & 129254 & 122631 & 123359 & 119583 & 119780 & 117480 & 112275 & 118803 & \\
\hline CD births $41-50$ & 26 & 20 & 31 & 27 & 16 & 24 & 26 & 25 & 20 & 23 & 21 & 19 & 278 \\
\hline $\begin{array}{l}\text { Exp CD births } \\
\quad 41-50\end{array}$ & 23.30 & 21.77 & 24.53 & 23.76 & 24.78 & 23.51 & 23.65 & 22.92 & 22.96 & 22.52 & 21.52 & 22.77 & \\
\hline Births $51-60$ & 118827 & 113138 & 128071 & 122211 & 126777 & 118837 & 119705 & 115822 & 115968 & 114244 & 107377 & 114030 & \\
\hline CD births $51-60$ & 34 & 35 & 35 & 36 & 49 & 31 & 29 & 33 & 27 & 32 & 21 & & 390 \\
\hline $\begin{array}{l}\text { Exp CD births } \\
51-60\end{array}$ & 32.75 & 31.18 & 35.30 & 33.68 & 34.94 & 32.75 & 32.99 & 31.92 & 31.96 & 31.49 & 29.59 & 31.43 & \\
\hline Births $61-70$ & 140152 & 132757 & 152520 & 141979 & 146563 & 139200 & 141715 & 138147 & 136317 & 134945 & 127271 & 133645 & \\
\hline CD births $61-70$ & 30 & 25 & 31 & 28 & 24 & 26 & 28 & 19 & 27 & 23 & 18 & 21 & 300 \\
\hline $\begin{array}{l}\text { Exp births CD } \\
\quad 61-70\end{array}$ & 25.25 & 23.92 & 27.48 & 25.58 & 26.40 & 25.08 & 25.53 & 24.89 & 24.56 & 24.31 & 22.93 & 24.08 & \\
\hline Total CD births & 90 & 80 & 97 & 91 & 89 & 81 & 83 & 77 & 74 & 78 & 60 & 68 & 968 \\
\hline Total Exp births & 81.30 & 76.87 & 87.31 & 83.03 & 86.12 & 81.34 & 82.17 & 79.73 & 79.48 & 78.32 & 74.05 & 78.28 & \\
\hline Obs/Exp & 1.11 & 1.04 & 1.11 & 1.10 & 1.03 & 1.00 & 1.01 & 0.97 & 0.93 & 1.00 & 0.81 & 0.87 & \\
\hline
\end{tabular}

Exp, expected; Obs, observed.

available for 1624 patients with CD: 670 in Leicestershire, 426 in Derby, 424 in Cardiff, and 104 in Tower Hamlets (table 1). The month of birth distribution of the CD cases was compared to that expected from population statistics. ${ }^{12}$ To avoid temporal changes in birth date distribution, three separate decades (1941-50, 1951-60, and 1961-70) were analysed during which time 968 CD patients were born. $\chi^{2}$ tests were performed and relative risk

Table 3 Observed (Obs) Crohn's disease (CD) births versus expected (Exp) by season

\begin{tabular}{llllll}
\hline & fan-Mar & Apr-fun & ful-Sep & Oct-Dec & Total \\
\hline CD births & 267 & 261 & 234 & 206 & \multirow{2}{*}{968} \\
Exp births & 245.48 & 250.49 & 241.39 & 230.65 & \\
Obs/Exp & 1.088 & 1.042 & 0.97 & 0.89 & \\
\hline
\end{tabular}

Table 4 Crohn's disease (CD) births versus expected by year halves

\begin{tabular}{lllll}
\hline & Observed CD & Expected CD & Obs/Exp & RR (95\% CI) \\
\hline Jan-June & 528 & 496.0 & 1.065 & $1.14(1.01-1.30)$ \\
July-Dec & 440 & 472.0 & 0.932 & \\
Total & 968 & 968 & & \\
\hline
\end{tabular}

Table 5 Total births, Crohn's disease (CD) births, adjusted CD birth rate, and measles notifications 1940-1967

\begin{tabular}{|c|c|c|c|c|}
\hline Year & Total births & Total CD births & $C D /$ total births ${ }^{\star} 1000$ & $\begin{array}{l}\text { Measles notifications } \\
(1000 \text { s) }\end{array}$ \\
\hline 1940 & 607 & 16 & 26.36 & 410 \\
\hline 1941 & 587 & 20 & 34.07 & 410 \\
\hline 1942 & 654 & 19 & 29.052 & 286 \\
\hline 1943 & 683 & 23 & 33.67 & 376 \\
\hline 1944 & 745 & 32 & 42.95 & 158 \\
\hline 1945 & 685 & 23 & 33.58 & 447 \\
\hline 1946 & 820 & 38 & 46.34 & 160 \\
\hline 1947 & 886 & 35 & 39.50 & 394 \\
\hline 1948 & 777 & 40 & 51.48 & 400 \\
\hline 1949 & 731 & 22 & 30.10 & 386 \\
\hline 1950 & 692 & 26 & 37.57 & 368 \\
\hline 1951 & 680 & 30 & 44.12 & 616 \\
\hline 1952 & 673 & 29 & 43.09 & 390 \\
\hline 1953 & 682 & 34 & 49.85 & 545 \\
\hline 1954 & 673 & 44 & 65.38 & 147 \\
\hline 1955 & 665 & 44 & 66.17 & 694 \\
\hline 1956 & 698 & 40 & 57.31 & 161 \\
\hline 1957 & 723 & 43 & 59.47 & 634 \\
\hline 1958 & 741 & 34 & 45.88 & 259 \\
\hline 1959 & 749 & 41 & 54.74 & 540 \\
\hline 1960 & 785 & 51 & 64.97 & 159 \\
\hline 1961 & 811 & 41 & 50.55 & 764 \\
\hline 1962 & 839 & 45 & 53.64 & 189 \\
\hline 1963 & 854 & 42 & 49.18 & 601 \\
\hline 1964 & 876 & 28 & 31.96 & 307 \\
\hline 1965 & 863 & 34 & 39.40 & 502 \\
\hline 1966 & 850 & 32 & 37.65 & 344 \\
\hline 1967 & 832 & 22 & 26.44 & 460 \\
\hline
\end{tabular}

(RR) and 95\% confidence intervals (CI) calculated using confidence interval analysis software. $^{13}$

The preferred model that fits well many seasonal and other cyclical trends is known as the von Mises distribution, as described by Mardia. ${ }^{14}$ Using this model, the number of cases born in each month is fitted by a constant and a sinusoidal term, with time of peak fitted to the observed data. The model has two degrees of freedom, which is the minimum that is meaningful; one of the fitted parameters represents the time of the peak, the other the amplitude. In this instance, because the numbers of births were different at different times of the year (not only because the lengths of the months are unequal), the number of cases in each birth month category were first adjusted slightly so that they still added up to the correct total (968) but took account of the expected values.

Data on yearly incidence of measles was obtained from the Public Health Laboratory Service from 1940-1997. ${ }^{15}$ During the period 1951-67, measles notifications exhibited an almost perfect biennial pattern with over 450000 notifications in odd years and less than 400000 in even years. CD cases were compared between odd and even birth years in this period, taking account of changing numbers of total births per year. The relative risk in epidemic years relative to non-epidemic years was calculated (with $95 \% \mathrm{CI}$ ). ${ }^{16}$

\section{Results}

Results are displayed in table 2. There appeared to be an excess of births in spring, especially in the 1940s. Analysis of individual months revealed no statistically significant differences from expected totals. Analysis using the von Mises distribution gave an estimated peak at $102^{\circ}$ relative to a turn of year reference point (that is, 12 April; $\chi_{2}^{2}=4.11, \mathrm{p}=0.13$ ).

When the data were analysed by season (table 3) and individual decades summated, the ratios of observed to expected CD births were $1.088,1.042,0.969$, and $0.893\left(\chi_{3}^{2}=5.19\right.$, $\mathrm{p}>0.05)$. The data only became significantly different if analysed by first and second halves of the year, which showed observed versus expected ratios of 1.065 and $0.932\left(\chi^{2}=4.24\right.$, 
Table 6 Crohn's disease (CD) births in odd years versus even years for the years 1951-67

\begin{tabular}{lllll}
\hline & Observed $C D$ & Expected $C D$ & Obs/Exp & RR (95\% CI) \\
\hline Odd years & 331 & 334.7 & 0.989 & $0.98(0.84-1.14)$ \\
Even years & 303 & 299.3 & 1.012 & \\
Total & 634 & 634 & & \\
\hline
\end{tabular}

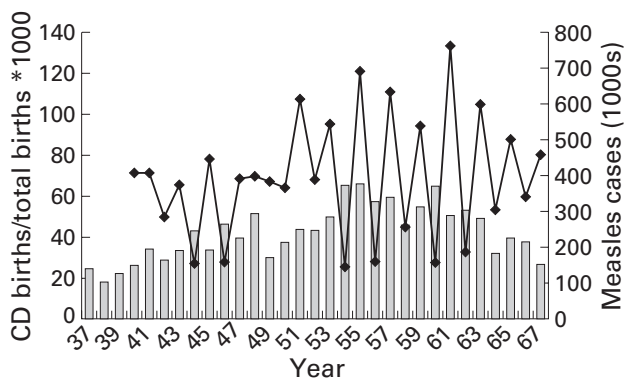

Figure 1 Measles notifications versus adjusted Crohn's disease (CD) birth rate by year.

$\mathrm{p}=0.039)$. This is demonstrated in table 4 , with a relative risk of 1.14 (95\% CI 1.01-1.30).

The number of measles notifications per year and CD cases born in those years are shown in table 5 . CD cases are divided by total births in those years (multiplied by 1000) to produce an adjusted $\mathrm{CD}$ birth rate. The number of $\mathrm{CD}$ cases born in odd and even years during the period 1951-67 is shown in Figure 1. There was no significant difference in the proportion of $\mathrm{CD}$ cases between epidemic and nonepidemic years $\left(\chi_{1}^{2}=0.17 ; \mathrm{p}=0.68\right)($ table 6$)$. The estimated relative risk in a measles year was 0.98 (95\% CI 0.84-1.14).

\section{Discussion}

Our results demonstrated no seasonal variation in the month of birth of patients who subsequently developed CD. Only when the data were analysed by year halves did a significant difference from expected arise and here the lower confidence limit for the relative risk (1.14) was only just greater than unity (1.01-1.30). With regard to measles, there was no evidence of any difference in incidence between epidemic and non-epidemic year births as would be expected whatever the hypothetical age of the patients subsequently.

We do not feel that the weak association we have demonstrated between births in year halves supports the hypothesis that early exposure to seasonal environmental factors may be of substantial aetiological importance. How- ever, this seasonality has been reported previously. In a study of 1469 CD cases and 2509 ulcerative colitis (UC) cases diagnosed between 1945 and 1954, Ekbom and colleagues found that there was an increased risk of developing both CD and UC in those born in the first half of the year. ${ }^{17}$ The authors linked excess of births in the first half of the year in the Swedish study to influenza epidemics but a similar study in the $\mathrm{UK}^{18}$ found no association with measles epidemics and birth date and this is supported by the results of our data.

We believe our data suggest that in utero or perinatal exposure to seasonal environmental factors are unlikely potential aetiological agents in the later development of $\mathrm{CD}$ and that early exposure to measles is very unlikely to be implicated in the aetiology of CD.

1 Rose JDR, Roberts GM, Williams G, et al. Cardiff Crohn's disease jubilee: the incidence over 50 years. Gut 1988;29:346-51

2 Ekbom A, Wakefield AJ, Zack M, et al. Perinatal measles infection and subsequent Crohn's disease. Lancet 1994; 344:508-10.

3 Thompson NP, Montgomery SM, Pounder RE, et al. Is measles vaccination a risk factor for inflammatory bowel disease? Lancet 1995;345:1071-4.

4 Wakefield AJ, Murch SH, Linnell AAJ, et al. Ileal-lymphoid nodular hyperplasia, non-specific colitis and pervasive

development disorder in children. Lancet 1998;351:37-41.

Probert CS, Jayanthi V, Hughes AO, et al. Prevalence and family risk of ulcerative colitis and Crohn's disease: an epidemiological study among Europeans and South Asians in
Leicestershire. Gut 1993;34:1547-51.

6 Probert CSJ, Jayanthi V, Pollock D, et al. Crohn's disease in Bangladeshis and Europeans in Britain: an epidemiological comparison in Tower Hamlets. Postgrad Med $\mathcal{F}$ 1992;68: $914-21$

7 Jayanthi V, Probert CSJ, Pollock D, et al. Low incidence of ulcerative colitis and proctitis in Bangladeshi migrants in Britain. Digestion 1992;52:34-42.

8 Srivastava ED, Mayberry JF, Morris TJ, et al. Incidence of ulcerative colitis in Cardiff over 20 years: 1968-87. Gut 1992;33: 256-38.

9 Thomas GA, Millar-Jones D, Rhodes J, et al. Incidence of Crohn's disease in Cardiff over 60 years: 1986-90 an update. Eur $\mathcal{F}$ Gasroenterol Hepatol 1995;7:401-5.

10 Fellows IW, Freeman JG, Holmes GKT. Crohn's disease in the city of Derby, 1951-1985. Gut 1990;31:1262-5.

11 Lennard-Jones JE. Classification of inflammatory bowel disLennard-Jones JE. Classification of inflammatory bowe
ease. Scand f Gastroenterol 1989;24(suppl 170):2-15.

12 Office of Population Censuses and Surveys. Birth statistics. London: HMSO, 1986.

13 Gardner MJ, Altman DG. Calculating confidence intervals for relative risk, odds ratios, and standardised ratios and rates. Statistics with confidence. London: BMJ 1989:50-63.

14 Mardia KV. Statistics of directional data. London: Academic Press, 1972.

15 Office of Population Censuses and Surveys. Communicable disease statistics (series MB2 No 6). London: HMSO, 1970: figure 5 , p xiii.

16 Newcombe RG. Interval estimation for the difference between independent proportions: comparison of eleven methods. Stat Med 1998;17:873-90.

17 Ekbom A, Helmick C, Zack M, et al. The epidemiology of inflammatory bowel disease: a large population-based inflammatory bowel disease: a large population-b.

18 Thompson NP, Pounder RE, Wakefield AJ. Perinatal and childhood risk factors for inflammatory bowel disease: a case-control study. Eur f Gastroenterol Hepatol 1995;7:401- 